\title{
THE NOVEL ANTIHYPERGLYCAEMIC ACTION OF HUNTERIA UMBELLATA SEED FRACTIONS MEDIATED VIA INTESTINAL GLUCOSE UPTAKE INHIBITION
}

\author{
Adeneye A. A. ${ }^{1,2}$,*, Adeyemi O. O. ${ }^{2}$, Agbaje E.O. ${ }^{2}$, Sofidiya M. O. ${ }^{3,}$ \\ ${ }^{1}$ Department of Pharmacology, Faculty of Basic Medical Sciences, Lagos State University College of \\ Medicine, Ikeja, Lagos State, Nigeria, ${ }^{2}$ Department of Pharmacology, Faculty of Basic Medical \\ Sciences, College of Medicine, University of Lagos, Idi-Araba, Lagos State, Nigeria ${ }^{3}$ Department of \\ Pharmacognosy, Faculty of Pharmacy, University of Lagos, Idi-Araba, Lagos State, Nigeria \\ *E-mail: adeneye2001@yahoo.com
}

\begin{abstract}
The present study evaluated the antihyperglycaemic effect and mechanism of action of fractions of the aqueous seed extract of Hunteria umbellata (K. Schum.) Hallier f. (HU) in normal and alloxan-induced hyperglycaemic rats. $H U$ was partitioned in chloroform, acetyl acetate and butan-1-ol to give chloroform fraction $\left(H U_{\mathrm{c}}\right)$, ethyl acetate fraction $\left(H U_{\mathrm{e}}\right)$, butanol fraction $\left(H U_{\mathrm{b}}\right)$ and the "residue" $\left(H U_{\mathrm{m}}\right)$, respectively. $200 \mathrm{mg} / \mathrm{kg}$ of each of these fraction dissolved in $5 \%$ Tween 20 in distilled water was investigated for its acute oral hypoglycaemic effects in normal rats over 6 hours while its repeated dose antihyperglycaemic effect was evaluated in alloxan-induced hyperglycaemic rats over 5 days. In addition, $50 \mathrm{mg} / \mathrm{kg}$ of the crude alkaloid fraction $\left(H U_{\mathrm{Af}}\right)$ extracted from $H U$ was evaluated for its possible antihyperglycaemic activity in alloxaninduced hyperglycaemic rats using oral glucose tolerance test (OGTT) over 6 hours. Using the solvent system, distilled water-butanol-ammonium hydroxide $(2: 15: 1, \mathrm{v} / \mathrm{v} / \mathrm{v}), H U_{\mathrm{b}}$ was chromatographed and stained with Dragendorff's reagent for confirmatory qualitative analysis for alkaloids. Results showed that oral pre-treatment with $200 \mathrm{mg} / \mathrm{kg}$ of $H U_{\mathrm{e}}, H U_{\mathrm{b}}$ and $H U_{\mathrm{m}}$ resulted in a significant $(p<0.05, p<0.001)$ time dependent hypoglycaemic effect, with the butan-1-ol fraction $H U$ causing the most significant $(p<0.001)$ hypoglycaemic effect. In the alloxan-induced hyperglycaemic rats, repeated oral treatment with $200 \mathrm{mg} / \mathrm{kg}$ of same $H U$ fractions for 5 days resulted in significant $(p<0.05)$ decreases in the fasting blood glucose concentrations with the most significant $(p<0.01)$ antihyperglycaemic effect also recorded for $H U_{\mathrm{b}}$. Similarly, oral pretreatment with $50 \mathrm{mg} / \mathrm{kg}$ of $H U_{\mathrm{Af}}$ significantly $(p<0.05, p<0.01$ and $p<0.001)$ attenuated an increase in the post-absorptive glucose concentration at $1^{\text {st }}-6^{\text {th }} \mathrm{h}$ in the alloxan-induced hyperglycaemic OGTT model. In addition, alkaloid was present in most of the separated spots on the TLC plate. In conclusion, results of this study showed that $H U$ contains a relative high amount of alkaloids which could have accounted for the antihyperglycaemic action of $H U$ that was mediated via intestinal glucose uptake inhibition.
\end{abstract}

Key words: Hunteria umbellata aqueous seed extract, Alkaloid fraction, Intestinal glucose uptake inhibition, Normal and alloxan-induced hyperglycaemic rats

List of Abbreviations: $\mathrm{C}_{4} \mathrm{H}_{9} \mathrm{OH}=$ butan-1-ol; $\mathrm{dH}_{2} \mathrm{O}=$ distilled water; $\mathrm{HCl}=$ hydrochloric acid; $H U$ = aqueous seed extract of Hunteria umbellata (K. Schum.) Hallier f.; $H U_{\mathrm{Af}}=$ alkaloid fraction of $H U ; H U_{\mathrm{b}}$ = butan-1-ol fraction of $H U$; $H U_{\mathrm{c}}=$ chloroform fraction of $H U ; H U_{\mathrm{e}}=$ ethyl acetate fraction of $H U ; H U_{\mathrm{m}}=$ "residue" fraction of $H U ; \mathrm{Na}_{2} \mathrm{CO}_{3}=$ sodium bicarbonate; $\mathrm{NH}_{4} \mathrm{OH}=$ ammonium hydroxide; $\mathrm{R}_{\mathrm{f}}=$ retention factor $; \mathrm{TLC}=$ thin layer chromatography; $\mathrm{UV}=$ ultraviolet light

\section{Introduction}

Hunteria umbellata (K. Schum.) Hallier f. (family: Apocynaceae) is a tropical rainforest tree which closely resembles Picralima umbellata K. Schum., Polyadoa umbellata (K. Schum.) Stapf., Hunteria elliotii (Stapf.) Pichon, Picralima nitida, Picralima elliotii (Stapf.) Stapf., and Picralima gracilis A. Chev. (Hutchinson and Dalziel, 1963). In Nigeria, the plant is ubiquitous to the South-west region where it is locally known as "Abeere" among the Yorubas and the Binis while in French it is known as "Demouain" (Bouquet and Debray, 1974; Boone, 2006).

Ethnomedical uses of Hunteria umbellata (K. Schum.) Hallier f. include treatment of yaws and sexually transmitted infections, stomach ache and ulcers, diabetes mellitus and dysmenorrhoea (Falodun et al., 2006). In South-west Nigeria, traditional birth attendants/midwives employ the fresh leaves and pulp of fresh fruits of Hunteria umbellata in the induction and/or augmentation of labour in gravid uterus at term (Falodun et al., 2006). Hot and cold decoctions made from the plant seeds have also been reported to be highly valued in the local treatment of obesity, hypertension, pain and swellings, anaemia and as immune booster (Boone, 2006; Adeneye and Adeyemi, 2009a; 2009b).

Previous studies have reported the antihyperglycaemic (Adeneye and Adeyemi, 2009a; 2009b; Igbe et al., 2009), anti-obesity and antihyperlipidaemic (Adeneye et al., 2010) effects of the crude aqueous seed extract of Hunteria umbellata $(H U)$ in rats. In furthering our investigation of the antihyperglycaemic effect of $H U$, the present study is aimed at separating and investigating the possible antihyperglycaemic effect of the solvent fractions of $H U$ in normal and alloxan-induced 
hyperglycaemic rats. In addition, qualitative analysis of the most active fraction of $H U$ was conducted on thin layer chromatography. The choice of dose used was based on the results of previous studies.

\section{Materials and methods \\ Plant material}

Collection, identification, authentication and the extraction process of Hunteria umbellata with voucher no.: FHI 107687 were done as previously described by Adeneye and Adeyemi (2009a).. The extraction process was done as previously reported by Adeneye and Adeyemi (2009b).

\section{Solvent partitioning of $\mathrm{HU}$}

$30 \mathrm{~g}$ of the extract was dissolved completely in $100 \mathrm{ml}$ of distilled water. The solution was then transferred into 5 litre burette before it was partitioned using between 1 litre to 1.5 litres of different partitioning solvents (diethyl ether, chloroform, ethyl acetate and butan-1-ol) in the order of their increasing solubility gradients. The fraction obtained with each partitioning solvent was concentrated in vacuo using rotary evaporator (B'U ${ }^{\cdot} \mathrm{CHI}$ Rotavapor ${ }^{\circledR}$ Model R-215, Switzerland) with Vacuum Module V-801 EasyVac ${ }^{\mathbb{B}}$, Switzerland) set at a revolution of $70 \mathrm{rpm}$ and a temperature of $35^{\circ} \mathrm{C}$. The "Marc" and the concentrate of each fraction were then transferred to an aerated oven preset at $35{ }^{\circ} \mathrm{C}$ for complete dryness. The residues left after oven drying were then weighed. This procedure was repeated thrice and each residue was pooled together and stored in clean and dry, water and air-proof containers and preserved in the refrigerator until required for experimentation.

\section{Qualitative analytical TLC method for $\mathrm{HU}_{b}$}

Thin layer chromatography (TLC) analysis of $H U_{\mathrm{b}}$ was performed using TLC plates which were cut along lines into three parts $(10 \times 3 \mathrm{~cm})$ and dried in a drying oven at $100-105{ }^{\circ} \mathrm{C}$ for $1 \mathrm{~h}$. Plates were activated before-hand in a drying oven for at least $1 \mathrm{~h}$ at $100-105^{\circ} \mathrm{C}$ for sharp separation of the components. The chromatographic chamber was saturated with vapour of the solvent system for $24 \mathrm{~h}$ for the same purpose. $0.02 \mathrm{ml}$ of the extract was deposited at the origin of the TLC paper using a micropipette. The plate with the deposited samples was air-dried for $5 \mathrm{~min}$, placed in the chromatography chamber saturated with water: butanol: ammonium hydroxide solution $\left(\mathrm{dH}_{2} \mathrm{O}: \mathrm{C}_{4} \mathrm{H}_{9} \mathrm{OH}: \mathrm{NH}_{4} \mathrm{OH}\right)$ solvent system at the ratio of 2:15:1 (v/v/v), and chromatographed in an ascending mode. When the solvent front reached about $9 \mathrm{~cm}$, the plate was removed from the chamber and air-dried for $5 \mathrm{~min}$. The plate was examined in UV light at wavelength $366 \mathrm{~nm}$ before and after treatment with Dragendorff's solution for the identification of alkaloids in the extract. A colour change on the TLC plate was then recorded. The ratio of the distance moved each of separated spot (solute) relative to the distance moved by the solvent (solvent front) is expressed as the retention factor $\left(\mathrm{R}_{\mathrm{f}}\right)$.

\section{Extraction of the crude alkaloid fraction $\left(\mathrm{HU}_{\mathrm{Af}}\right)$ from $\mathrm{HU}$}

$4.14 \mathrm{~g}$ of $H U$ in $10 \mathrm{ml}$ of distilled water $(\mathrm{pH}=4.2)$ was repeatedly titrated with $50 \mathrm{ml}$ of $5 \%$ aqueous $\mathrm{HCl}$ solution to acidify the solution to a $\mathrm{pH}$ of 2 . The acidify solution was extracted with chloroform $(150 \mathrm{ml} \times 3)$ to remove the neutral compounds in the acidify $H U$ solution. The acidify $H U$ solution was carefully basified with $5 \%$ sodium bicarbonate $\left(\mathrm{Na}_{2} \mathrm{CO}_{3}\right)$ solution to $\mathrm{pH} 10$. Using a separating funnel, the mixture extracted repeatedly with small portions of chloroform $(150 \mathrm{ml} \times 3)$ until the last extract was almost colourless and the basic solution gave negative tests with alkaloid detecting reagents. The chloroform extracts were combined followed by evaporation at the room temperature $\left(32{ }^{\circ} \mathrm{C}\right)$ to give total alkaloid fraction (a very deep brown solid residue) weighing $0.30 \mathrm{~g}$ (yield: 7.25\%) (Yang et al., 1999; Adeoye and Oyedapo, 2004). This procedure was repeated thrice and the total alkaloid fraction pooled together into a tight-capped container which was stored in the refrigerator until required for experiment.

\section{Experimental animals}

Healthy young adult male albino Wistar rats (100-130 g) used in this study were obtained from the Animal House of the Lagos State University College of Medicine, Ikeja, Lagos State, Nigeria after an ethical approval for the study has been obtained. The rats were housed in polypropylene cages and handled in accordance with international principles guiding the Use and Handling of experimental animals (United States National Institutes for Health, 1985). Rat feed (Ladokun Feeds, Ibadan, Nigeria) and tap water were provided ad libitum. The rats were maintained at an ambient temperature between 28-30 ${ }^{\circ} \mathrm{C}$, humidity of $55 \pm 5 \%$, and standard (natural) photoperiod of approximately $12 \mathrm{~h}$ of light $(06: 30 \mathrm{~h}-18: 30 \mathrm{~h})$ alternating with approximately 12 hours of darkness $(18: 30 \mathrm{~h}-06: 30 \mathrm{~h})$.

\section{Determination of the oral hypoglycaemic effect of the fractions of $\mathrm{HU}$ in normal rats}

To identify the biologically active fraction(s) of $H U, 1 \mathrm{~g}$ of the marc, chloroform fraction, acetyl acetate fraction and butan-1-ol fraction each were dissolved in $10 \mathrm{ml}$ of 5\% Tween-20 in distilled water to make a concentration of 100 $\mathrm{mg} / \mathrm{ml}$ solution. $5 \%$ Tween-20 in distilled water was used as the solvent in this case because of the insolubility of the fractions in distilled water. Thirty, young in-bred adult male white albino Wistar rats (100-130 g) were randomly allotted to 6 groups. The rats were then fasted overnight for 12-14 hours but had free access to drinking water. The basal fasting blood glucose of each rat was first determined using One Touch Basic Blood Glucose Monitoring System ${ }^{\circledR}$ (LifeScan Inc., Milpitas, California, U.S.A.). This was then followed by the following treatments: Group I rats were orally administered $10 \mathrm{ml} / \mathrm{kg}$ of 
5\% Tween-20 in distilled water; Group II rats were orally treated with $1 \mathrm{mg} / \mathrm{kg}$ of glibenclamide while Group III-VI rats were orally treated with $200 \mathrm{mg} / \mathrm{kg}$ of chloroform fraction $\left(H U_{\mathrm{c}}\right)$, ethyl acetate fraction $\left(H U_{\mathrm{e}}\right)$, butan-1-ol fraction $\left(H U_{\mathrm{b}}\right)$ and the "residue" $\left(H U_{\mathrm{m}}\right)$, respectively. The effect of each extract fraction on the blood glucose concentration was monitored at 0 h, 1 h, 2 h, 3 h, 4 h and 6 h post-treatment.

\section{Determination of the antihyperglycaemic effect of $H U$ fractions in alloxan-induced hyperglycaemic rats}

The antihyperglycaemic activity of the extract fractions was evaluated in alloxan-induced hyperglycaemic rats using the method of Vats et al. (2004). After $24 \mathrm{~h}$ fasting, a single dose of $120 \mathrm{mg} / \mathrm{kg}$ of alloxan monohydrate (Sigma Chemical Company, St. Louis, U.S.A.) dissolved in $3 \mathrm{mM}$ of freshly prepared cold citrate buffer $(\mathrm{pH}=4.5)$ was injected into 40 male Wistar rats. The baseline fasting blood glucose was first determined before alloxan treatment. Six hours after alloxan injection, rats were orally infused with $20 \%$ Dextrose (Unique Pharmaceuticals, Sango-Otta, Ogun State, Nigeria) at an oral dose of $10 \mathrm{ml} / \mathrm{kg}$ so as to prevent the onset of fatal hypoglycaemia which often accompanies administration of alloxan as a result of acute massive pancreatic release of insulin (Prince and Menon, 2001). Gradual onset of hyperglycaemia was confirmed on the $3^{\text {rd }}$ day post-induction but all the rats became consistently hyperglycaemic and stable by the $5^{\text {th }}$ day postinduction. By the $5^{\text {th }}$ day, rats with fasting blood glucose of equal or greater than $200 \mathrm{mg} / \mathrm{dl}$ were considered hyperglycaemic. Thirty-seven of the alloxan-treated rats had the fasting blood glucose concentration over $200 \mathrm{mg} / \mathrm{dl}$ while the remaining three rats had spontaneous resolution of their hyperglycaemia. Five normal and thirty-five alloxan-induced hyperglycaemic rats were randomly allocated into 7 treatment groups as follows: Group I consists of normoglycaemic rats which were orally treated with $10 \mathrm{ml} / \mathrm{kg}$ of $5 \%$ Tween 20 dissolved in distilled water; Group II consists of alloxan-induced hyperglycaemic rats orally treated with $10 \mathrm{ml} / \mathrm{kg}$ of $5 \%$ Tween 20 in distilled water; Group III consists of alloxan-induced hyperglycaemic rats orally pre-treated with $1 \mathrm{mg} / \mathrm{kg}$ of glibenclamide (Daonil ${ }^{\mathbb{Q}}$, Hoechst Marion Roussel Limited, Mumbai, India) dissolved in $5 \%$ Tween 20 in distilled water; Groups IV-VII consist of alloxan-induced hyperglycaemic rats orally pre-treated with 200 $\mathrm{mg} / \mathrm{kg}$ of chloroform, ethyl acetate, butan-1-ol fractions and the "marc", respectively. All treatments lasted 5 days after which the fasting blood glucose was determined using the glucose oxidase method on a One Touch Basic Blood Glucose Monitoring System.

\section{Determination of the hypoglycaemic effect of $\mathrm{HU}_{A f}$ in normal and alloxan- induced hyperglycaemic rats}

After 24 hours of fasting, thirty adult male Wistar rats (weighing 110-125 g) were made hyperglycaemic with intraperitoneal injection of $120 \mathrm{mg} / \mathrm{kg}$ alloxan monohydrate (Sigma Chemical Company, St. Louis, U.S.A.) in cold citrate buffer $(\mathrm{pH}=4.5$ ) using methods of Srivastava et al. (1988) and Vats et al. (2004). Stable hyperglycaemia was confirmed after 5 days post induction. Only rats with the fasting blood glucose concentration of $200 \mathrm{mg} / \mathrm{dl}$ were used for this study. Normal and alloxan-induced hyperglycaemic rats were randomly allocated into treatment groups as follows:Group I: normoglycaemic rats orally treated with $10 \mathrm{ml} / \mathrm{kg}$ of distilled water; Group II: normoglycaemic rats pre-treated with $10 \mathrm{ml} / \mathrm{kg}$ of $5 \%$ Tween 20 in distilled water 1 hour before oral treatment with $3 \mathrm{~g} / \mathrm{kg}$ of D-Glucose (BDH Chemicals, Poole, England); Group III: alloxan-induced hyperglycaemic rats orally pre-treated with $10 \mathrm{ml} / \mathrm{kg} 5 \%$ Tween 20 dissolved in distilled water; Group IV: alloxan-induced hyperglycaemic rats orally pre-treated with $10 \mathrm{ml} / \mathrm{kg} 5 \%$ Tween 20 dissolved in distilled water 1 hour before oral treatment with $3 \mathrm{~g} / \mathrm{kg}$ of D-Glucose; Group V: alloxan-induced hyperglycaemic rats orally pre-treated with 1 $\mathrm{mg} / \mathrm{kg}$ of glibenclamide (Daonil ${ }^{\mathbb{R}}$, Hoechst Marion Roussel Limited, Mumbai, India) dissolved in 5\% Tween 20 in distilled water 1 hour before oral treatment with $3 \mathrm{~g} / \mathrm{kg}$ of D-Glucose; Group VI: alloxan-induced hyperglycaemic rats orally pretreated with $50 \mathrm{mg} / \mathrm{kg}$ of $H U_{\mathrm{Af}}$ dissolved in $5 \%$ Tween 20 in distilled water 1 hour before oral treatment with $3 \mathrm{~g} / \mathrm{kg}$ of DGlucose. Following the oral administration of the drugs and the extract fraction, their effects on the blood glucose concentration was monitored at $0 \mathrm{~h}, 1 \mathrm{~h}, 2 \mathrm{~h}, 3 \mathrm{~h}, 4 \mathrm{~h}$ and $6 \mathrm{~h}$ post-treatment. Blood glucose concentration of each rat was determined as described above.

\section{Statistical Analysis}

Results were expressed as mean \pm S.E.M. of six observations. Statistical analysis was done using two-way analysis of variance followed by post-hoc test, Student-Newman-Keuls test on SYSTAT 10.6. Statistical significance were considered at $p<0.05, p<0.01$, and $p<0.001$.

\section{Results}

\section{Solvent Partitioning of $\mathrm{HU}$}

Partitioning of $H U$ with diethyl ether, chloroform, ethyl acetate, and butan-1-ol and the eventual oven-drying of the fractions yielded $0 \mathrm{~g}$ of diethyl ether fraction (\%yield $=0 \%), 1 \mathrm{~g}$ of chloroform fraction (\%yield $=3.3 \%), 2 \mathrm{~g}$ of ethyl acetate fraction $(6.6 \%), 4 \mathrm{~g}$ of butan-1-ol fraction (\%yield $=13.3 \%)$ and $22 \mathrm{~g}$ of the "residue" (\%yield $=73.3 \%)$, all of which were insoluble in water.

\section{Qualitative analyses of the major phytochemicals in $\mathbf{H U}_{\mathbf{b}}$}

Using the developing solvent water-butanol-ammonium hydroxide $(2: 15: 1, \mathrm{v} / \mathrm{v} / \mathrm{v}) H U_{\mathrm{b}}$ was chromatographed and stained with Dragendorff's reagent to confirm the presence of alkaloids on TLC plate. Chromatographic separation of $H U_{\mathrm{b}}$ on TLC plate showed spots at different gradients but two distinctive heavy spots that fluorescent white- one at the middle of the spectrum $\left(y_{5}\right)$ (with $\mathrm{R}_{\mathrm{f}}$ value of 0.40 ) and the other at the upper end of the spectrum $\left(y_{10}\right)$ (with $\mathrm{R}_{\mathrm{f}}$ value of 0.93 ) when view 
under UV light (wavelength: $366 \mathrm{~nm}$ ) when compared to the chromatogram viewed under the visible light (Figure 1). After spraying with Dragendorff's reagent in the fume cupboard, spots $x_{1}, x_{2}, x_{4}, x_{5}, x_{6}, x_{9}$ (with $\mathrm{R}_{\mathrm{f}}$ values of $0.07,0.16,0.27,0.32$, $0.41,0.59$ respectively) turned deep orange-brown confirming the presence of alkaloids at these spots corresponding to spots $y_{1}, y_{2}, y_{3}, y_{4}, y_{5}, y_{8}$ (with $\mathrm{R}_{\mathrm{f}}$ values of $0.08,0.15,0.29,0.33,0.40,0.59$, respectively) on TLC before spraying with Dragendorff's reagent (Figure 2).

\section{Evaluation of the antihyperglycaemic effect of $H U$ fractions in normal rats}

Figure 3 and Table 1 show the acute effect of oral treatment with chloroform, ethyl acetate, butan-1-ol, and "residue") fractions of $H U$ on the blood glucose concentrations of normal and alloxan-induced hyperglycaemic rats, respectively. Oral treatment with $1 \mathrm{mg} / \mathrm{kg}$ glibenclamide, $200 \mathrm{mg} / \mathrm{kg} H U_{\mathrm{b}}$ and $200 \mathrm{mg} / \mathrm{kg} H U_{\mathrm{e}}, 200 \mathrm{mg} / \mathrm{kg}$ of $H U_{\mathrm{m}}$ caused significant $(p<0.05, p<0.001)$ time dependent hypoglycaemic effect, with the butan-1-ol fraction $H U$ causing the most significant $(p<0.001)$ hypoglycaemic effect, an effect which was greater than that of $1 \mathrm{mg} / \mathrm{kg}$ glibenclamide in normal. In addition, $H U_{\mathrm{b}}$ caused early onset of hypoglycaemic action within the $1^{\text {st }} \mathrm{h}$ of oral treatment and this became greater over the succeeding 5 hours. However, the hypoglycaemic effect of $H U_{\mathrm{m}}$ became only manifested between the $4^{\text {th }}$ and $6^{\text {th }} \mathrm{h}$ posttreatment (Figure 3).

In the alloxan-induced hyperglycaemic rats, repeated oral treatment with $200 \mathrm{mg} / \mathrm{kg}$ of each of the $H U$ fractions for 5 days resulted in significant $(p<0.05)$ decreases in the fasting blood glucose concentrations with the most significant $(p<0.01)$ hypoglycaemic effect recorded for $H U_{\mathrm{b}}$. This significant $(\mathrm{p}<0.01)$ hypoglycaemia was comparable to that recorded for glibenclamide (Table 1)

Table 1: Effect of 5 days of repeated oral administration of $200 \mathrm{mg} / \mathrm{kg}$ of $H U_{c}, H U_{e}, H U_{b}$ and $H U_{m}$ on the fasting blood glucose concentrations in alloxan-induced hyperglycaemic rats

\begin{tabular}{|c|c|c|c|}
\hline \multirow[t]{2}{*}{ Groups } & \multicolumn{2}{|c|}{ fasting blood glucose $(\mathrm{FBG})(\mathrm{mg} / \mathrm{dl})$ on } & \multirow[t]{2}{*}{$\%$ FBG inhibition } \\
\hline & day 1 & day 6 & \\
\hline I & $76.00 \pm 3.21$ & $77.60 \pm 0.93$ & $2.66 \pm 3.96$ \\
\hline II & $230.20 \pm 5.38^{\mathrm{c}}$ & $255.00 \pm 8.39^{\mathrm{c}, \mathrm{a}}$ & $10.69 \pm 1.42^{\mathrm{a}^{+}}$ \\
\hline III & $229.40 \pm 5.57^{\mathrm{c}}$ & $114.40 \pm 2.79^{\mathrm{e}}$ & $-50.12 \pm 0.56^{f}$ \\
\hline IV & $231.40 \pm 8.47^{\mathrm{c}}$ & $218.20 \pm 9.60^{\mathrm{d}}$ & $-5.79 \pm 1.34^{\mathrm{d}}$ \\
\hline V & $224.00 \pm 5.50^{\mathrm{c}}$ & $203.80 \pm 6.80^{\mathrm{d}}$ & $-9.09 \pm 1.03^{\mathrm{d}}$ \\
\hline VI & $221.80 \pm 6.71^{\mathrm{c}}$ & $116.20 \pm 5.67^{\mathrm{e}}$ & $-48.53 \pm 1.77^{\mathrm{f}}$ \\
\hline VII & $231.40 \pm 7.13^{\mathrm{c}}$ & $196.20 \pm 9.45^{\mathrm{d}}$ & $-15.37 \pm 1.96^{\mathrm{d}}$ \\
\hline
\end{tabular}

\footnotetext{
${ }^{\mathrm{c}}$ represents a significant increase at $p<0.001$ when compared to basal value at day 0 while ${ }^{\mathrm{d}, \mathrm{e}}$ and ${ }^{\mathrm{f}}$ represent significant decreases at $p<0.05, p<0.01$ and $p<0.001$, respectively, when compared to Group II values on day 6 and ${ }^{\mathrm{a}^{+}}$represents a significant increase at $p<0.05$ when compared to Group I and Group II values on day 0.

$\mathrm{I}=$ normoglycaemic rats $+10 \mathrm{ml} / \mathrm{kg}$ of $5 \%$ Tween 20 in distilled water; $\mathrm{II}=$ alloxan hyperglycaemic rats $+10 \mathrm{ml} / \mathrm{kg}$ of $5 \%$ Tween 20 in distilled water; III= alloxan hyperglycaemic rats $+1 \mathrm{mg} / \mathrm{kg}$ glibenclamide in $5 \%$ Tween 20 in distilled water $\mathrm{IV}=$ hyperglycaemic rats $+200 \mathrm{mg} / \mathrm{kg}$ of $H U_{\mathrm{c}}$ in $5 \%$ Tween 20 in distilled water; $\mathrm{V}=$ hyperglycaemic rats $+200 \mathrm{mg} / \mathrm{kg}$ of $H U_{\mathrm{e}}$ in 5\% Tween 20 in distilled water ; VI = hyperglycaemic rats $+200 \mathrm{mg} / \mathrm{kg}$ of $H U_{\mathrm{b}}$ in $5 \%$ Tween 20 in distilled water VII = hyperglycaemic rats $+200 \mathrm{mg} / \mathrm{kg}$ of $H U_{\mathrm{m}}$ in $5 \%$ Tween 20 in distilled water
}

\section{Evaluation of the antihyperglycaemic effect of $H U_{A f}$ in alloxan-induced hyperglycaemic rats}

Single oral administration of $3 \mathrm{~g} / \mathrm{kg}$ of glucose to normoglycaemic rats (Group II) resulted in a significant $(p<0.01$ ) increase in the post-absorptive glucose concentration which peaked within $1 \mathrm{~h}$ of administration when compared to untreated normoglycaemic rats (Group I) (Figure 4). The glucose levels in Group II rats gradually and time dependently decreased at $2^{\text {nd }}-6^{\text {th }} \mathrm{h}$ post-glucose treatment reaching its lowest peak at $4^{\text {th }} \mathrm{h}$ post-glucose loading. However, in the untreated alloxaninduced hyperglycaemic rats (Group IV), oral treatment with $3 \mathrm{~g} / \mathrm{kg}$ of glucose resulted in a significant $(p<0.001)$ increase in post-absorptive blood glucose concentration within the first 2 hours and remained consistently high throughout the study period (Figure 4). Pre-treatment with $50 \mathrm{mg} / \mathrm{kg}$ of $H U_{\text {Af }}$ significantly $(p<0.05)$ attenuated an increase in the post-absorptive glucose concentration at $1 \mathrm{~h}$ when compared to the basal value (Figure 4). Further significant $(p<0.01$ and $p<0.001)$ timerelated decreases in the post-absorptive glucose concentration were recorded at $2^{\text {nd }}-6^{\text {th }} \mathrm{h}$ with the most profound decrease recorded at the $6^{\text {th }} \mathrm{h}$ post-glucose treatment.

\section{Discussion}

The current study investigates the antihyperglycaemic potential of the solvent fractions of $H U$ in normal and alloxan-induced hyperglycaemic rats. The profound hypoglycaemic effect induced by the $200 \mathrm{mg} / \mathrm{kg}$ of butan-1-ol $H U$ fraction suggests that this fraction contains a high concentration of antihyperglycaemic phytoconstituent(s) that may account for the antihyperglycaemic effect of the crude aqueous seed extract of Hunteria umbellata (K. Schum.) Hallier $\mathrm{f}$. Evaluation 


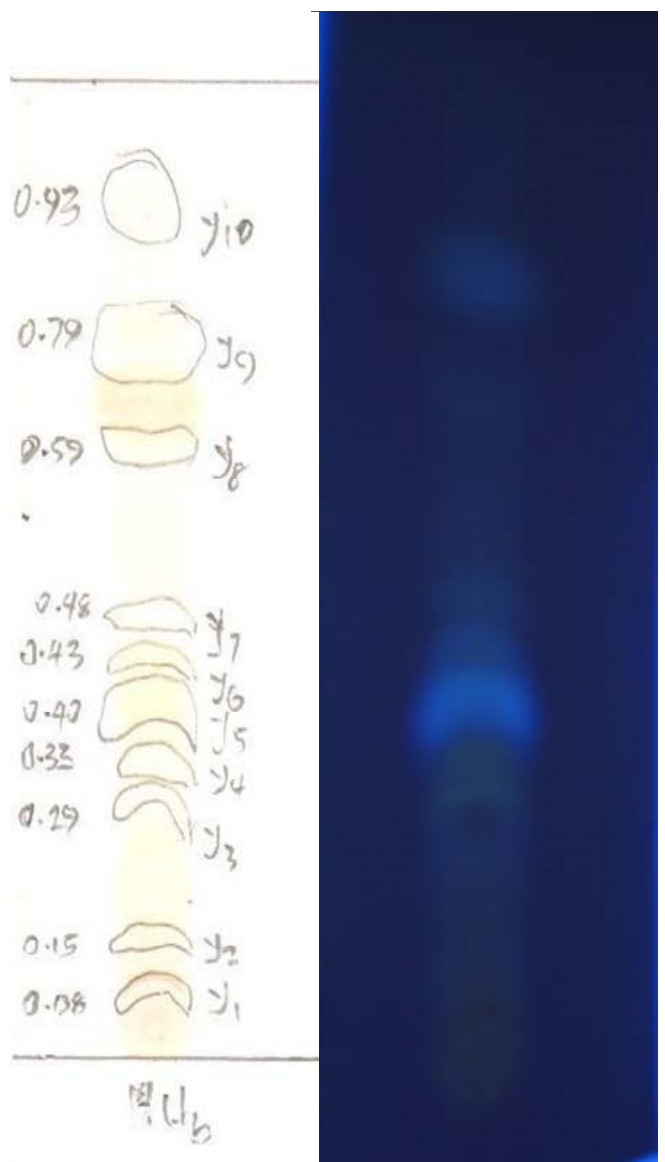

Figure 1: Comparative chromatograms of $H U$ butanol fraction $\left(H U_{\mathrm{b}}\right)$ viewed under visible light and UV light at wavelength of $366 \mathrm{~nm}$ showing the different spots of separation of $H U_{\mathrm{b}}$

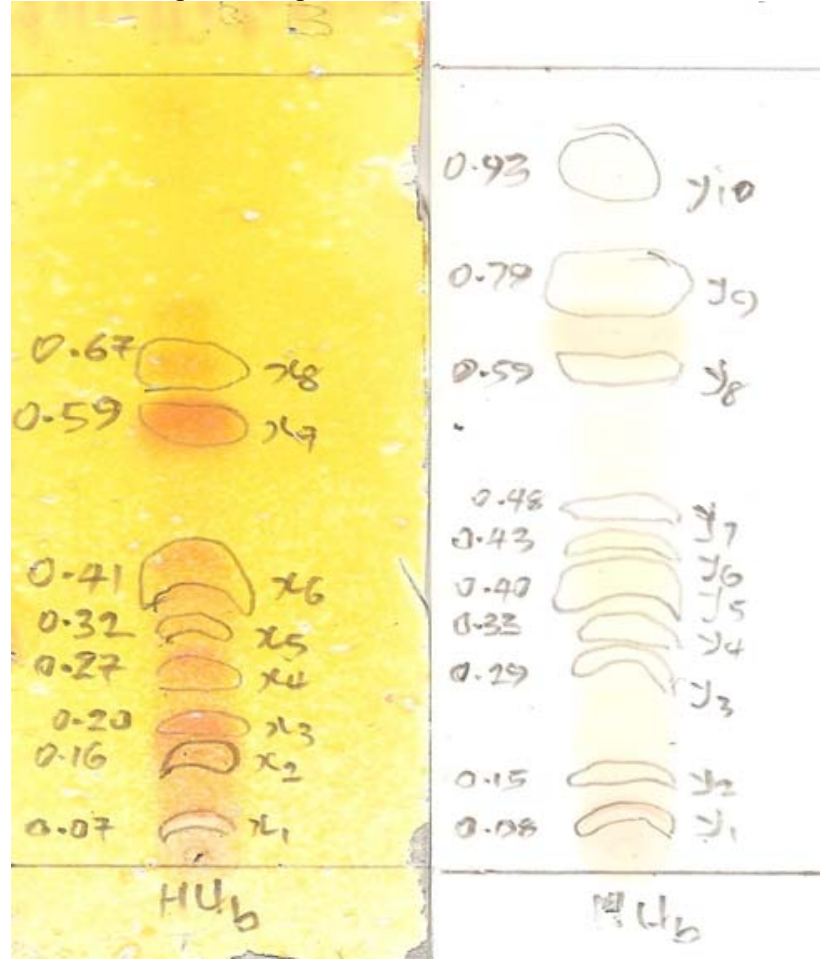

Figure 2: : Comparative chromatograms of $H U$ butanol fraction $\left(H U_{\mathrm{b}}\right)$ after and before staining with Dragendorff's reagent (b) to confirm the alkaloid portions of $H U_{\mathrm{b}}$ (indicated as deep orange-brown spots) on the TLC plate under visible light 


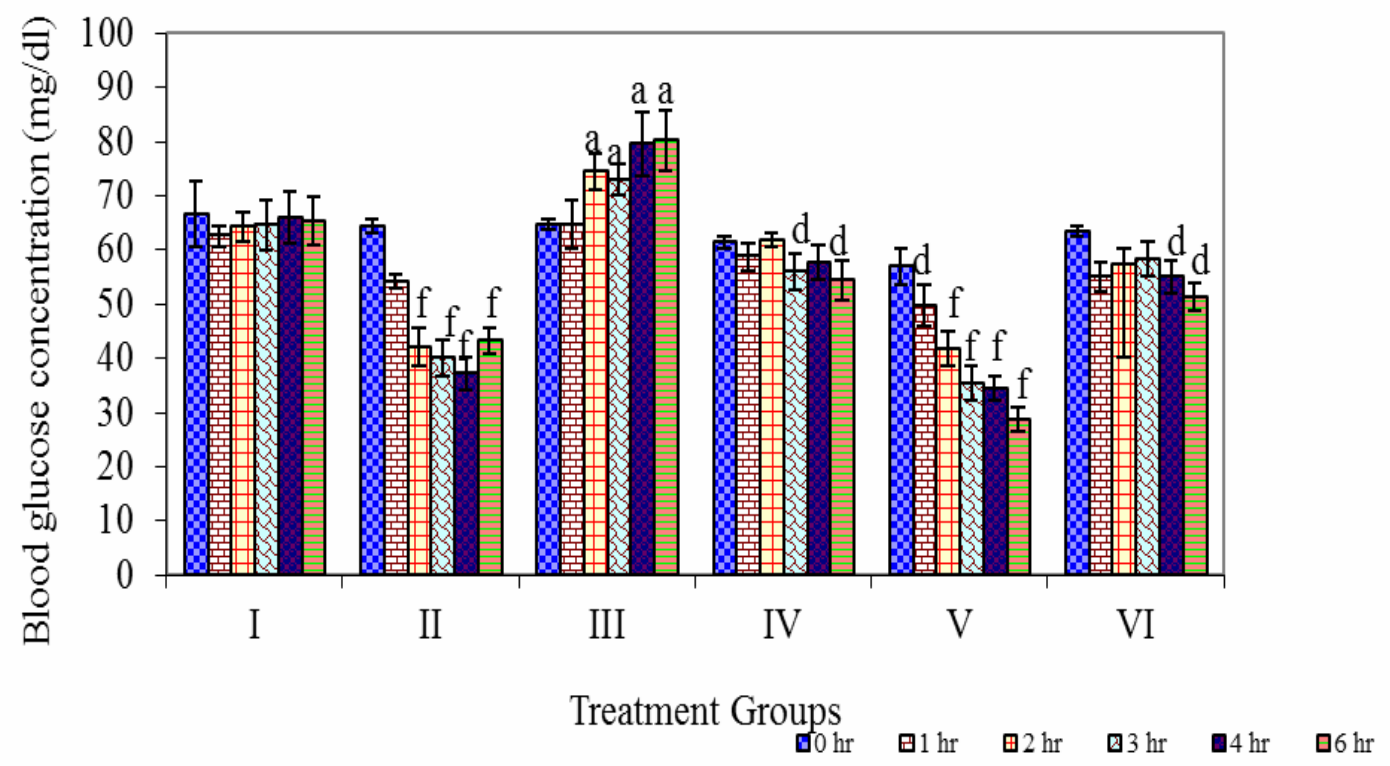

Figure 3: Effect of $200 \mathrm{mg} / \mathrm{kg}$ of $H U$ fractions on time-dependent blood glucose concentration (mg/dl) of normal rats ${ }^{\mathrm{d}}$ and ${ }^{\mathrm{f}}$ represent significant decreases at $p<0.05$ and $p<0.001$ while ${ }^{\mathrm{a}}$ represents a significant increase at $p<0.05$, respectively, when compared to the basal value

Group I = $10 \mathrm{ml} / \mathrm{kg} 5 \%$ Tween 20/distilled water; Group II = $1 \mathrm{mg} / \mathrm{kg}$ glibenclamide in 5\% Tween 20/distilled water Group III $=200 \mathrm{mg} / \mathrm{kg} H U_{\mathrm{c}}$ in $5 \%$ Tween 20/distilled water; Group IV $=200 \mathrm{mg} / \mathrm{kg} H U_{\mathrm{e}}$ in $5 \%$ Tween 20/distilled water Group V $=200 \mathrm{mg} / \mathrm{kg} H U_{\mathrm{b}}$ in $5 \%$ Tween 20/distilled water ;Group VI $=200 \mathrm{mg} / \mathrm{kg} H U_{\mathrm{m}}$ in $5 \%$ Tween 20/distilled water

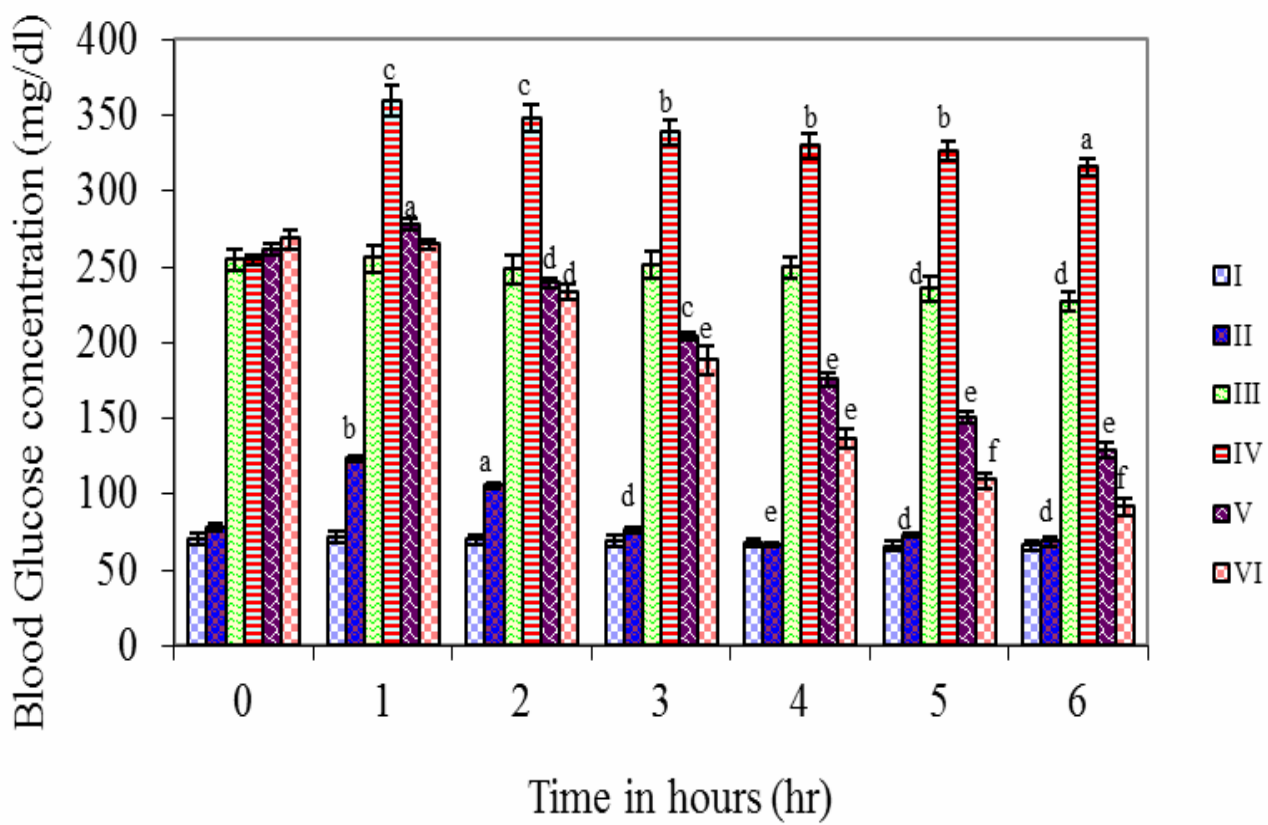

Figure 4: : Effect of $50 \mathrm{mg} / \mathrm{kg}$ of the crude alkaloid fraction $\left(H U_{\mathrm{Af}}\right)$ on oral glucose tolerance test (OGTT) in alloxaninduced hyperglycaemic rats

${ }^{\mathrm{a}, \mathrm{b}}$ and ${ }^{\mathrm{c}}$ represent significant increases at $p<0.05, p<0.01$ and $p<0.001$ when compared to the basal values at 0 hr while ${ }^{\mathrm{d}, \mathrm{e}}$ and ${ }^{\mathrm{f}}$ represent significant decreases at $p<0.05, p<0.01$ and $p<0.001$ when compared to values at $1 \mathrm{hr}$

$\mathrm{I}=$ normoglycaemic rats $+10 \mathrm{ml} / \mathrm{kg}$ of $5 \%$ Tween 20 in distilled water; II = normoglycaemic rats $+10 \mathrm{ml} / \mathrm{kg}$ of $5 \%$ Tween 20 in distilled water $+3 \mathrm{~g} / \mathrm{kg}$ D-Glucose; III = alloxan hyperglycaemic rats $+10 \mathrm{ml} / \mathrm{kg}$ of $5 \%$ Tween 20 in distilled water $\mathrm{IV}=$ alloxan hyperglycaemic rats $+3 \mathrm{~g} / \mathrm{kg}$ D-Glucose in $5 \%$ Tween 20 in distilled water; $\mathrm{V}=$ alloxan hyperglycaemic rats +1 $\mathrm{mg} / \mathrm{kg}$ of glibenclamide $+3 \mathrm{~g} / \mathrm{kg}$ D-Glucose $; \mathrm{VI}=$ alloxan hyperglycaemic rats $+50 \mathrm{mg} / \mathrm{kg}$ of $\left(H U_{\mathrm{Af}}\right)+3 \mathrm{~g} / \mathrm{kg}$ D-Glucose. 
of the alkaloid fraction in $H U$ showed that single oral treatment with this fraction caused profound antihyperglycaemia in the treated rats suggesting that $H U_{\mathrm{Af}}$ could be responsible for the antihyperglycaemic effect of the extract. This antihyperglycaemic effect was mediated via inhibition of intestinal glucose uptake mechanism since the $H U_{\mathrm{Af}}$ significantly attenuated an increase in the post-absorptive glucose concentrations in the alloxan-induced hyperglycaemic rats. Literature has shown that certain alkaloids induce hypoglycaemia via inhibition of intestinal glucose uptake by inhibiting $\alpha$-glucosidase activities (Yoshikawa et al., 2002; Fattorusso and Taglialatela-Scafati, 2007). In addition, it has been reported that medicinal plants rich in alkaloids usually exhibit hypoglycaemic activities (Svoboda et al., 1964; Yoshikawa et al., 2007; Okonta and Aguwa, 2007; Fuji et al., 2009). Thus, result of this study suggests that $H U_{\mathrm{Af}}$ could be mediating its oral hypoglycaemic effect through this mechanism, although other major phytocomponents in $H U_{\mathrm{b}}$ could be mediating their hypoglycaemic effects via other mechanisms.

Again, based on the higher number of spots positive for alkaloids, it could be deduced that $H U_{b}$ contains a higher amount alkaloids than other phytocomponents. Therefore, result of this study is in accord with the earlier report of Adegoke and Alo (1986). Although, quantification of these phytocomponents was not done in this study but this could constitute an area of future study. However, previous studies have reported intestinal glucose uptake inhibition as one of the mechanisms by which $H U$ lowers and control blood glucose (Adeneye and Adeyemi, 2009a; 2009b). From the results of the qualitative analyses of $H U_{b}$ on TLC coupled with that of in vivo antihyperglycaemic study, it could be deduced that alkaloids are responsible for intestinal glucose uptake inhibition mechanism of $H U$.

In conclusion, results suggest that alkaloids contained in $H U$ accounted for the antihyperglycaemic effect of the extract which was mediated via intestinal glucose uptake inhibition mechanism.

\section{Acknowledgements}

This study was partly supported by the Lagos State University College of Medicine, Ikeja, Lagos State, Nigeria, through the thesis support grant which was awarded to the corresponding author. The authors also acknowledge the support of the academic and technical staff of the Department of Pharmacognosy, Faculty of Pharmacy, University of Lagos, IdiAraba, Lagos State, Nigeria.

\section{References}

1 Adeneye, A.A. and Adeyemi, O.O. (2009a). Hypoglycaemic effects of the aqueous seed extract of Hunteria umbellata in normoglycaemic and glucose and nicotine-induced hyperglycaemic rats. International Journal of Natural Products Research 2(1): 9-18.

2 Adeneye, A.A. and Adeyemi, O.O. (2009b). Further evaluation of antihyperglycaemic activity of Hunteria umbellata (K. Schum) Hallier f. seed extract in experimental diabetes. Journal of Ethnopharmacology 126(2): 238-243.

3 Adeneye, A.A., Adeyemi, O.O. and Agbaje, E.O. (2010). Anti-obesity and antihyperlipidaemic effect of Hunteria umbellata seed extract in experimental hyperlipidaemia. Journal of Ethnopharmacology 130(2): 307-314.

4 Adegoke, E.A. and Alo, B. (1986). Abere-amines: Water soluble seed alkaloids from Hunteria umbellata. Phytochemistry 25(6): 1461-1468.

5 Adeoye, B.A. and Oyedapo, O.O. (2004). Toxicity of Erythrophleum guineense stem-bark: role of alkaloidal fraction. African Journal of Traditional, Complementary and Alternative Medicine 1: 45-54.

6 Boone, M.J. (2006). Hunteria umbellata (K. Schum.) Hallier f. In: Schmelzer, G.H. and Gurib-Fakim, A., editors. Prota 11: Medicinal plants/Plantes médicinales (CD-ROM). PROTA, Wageningen, Netherlands.

$7 \quad$ Bouquet, A. and Debray, M. (1974). Plantes médicinales de la Côte d'Ivoire. Travaux et Documents No 32, pp. 231. ORSTOM, Paris, France.

8 Falodun, A., Nworgu, Z.A.M. and Ikponmwonsa, M.O. (2006). Phytochemical components of Hunteria umbellata (K. Schum) and its effect on isolated non-pregnant rat uterus in oestrus. Pakistani Journal of Pharmaceutical Sciences 19(3): 256-258.

9 Fattorusso, E. and Taglialatela-Scafati, O. (2007). Glycosidase-inhibiting alkaloids: isolation, structure and application. In: Modern alkaloids: structure, isolation, synthesis and biology. Wiley-VCH Verlag GmbH and Company, Weinheim, Germany, pp. 111-133.

10 Fuji, M., Takei, I. and Umezawa, K. (2009). Antidiabetic effect of orally administered conophylline-containing plant extract on streptozotocin-treated and Goto-Kakizaki rats. Biomedical Pharmacotherapy 63(10): 710-716.

11 Hutchinson, J. and Dalziel, J.M., 1963. Hunteria. In: Flora of West Tropical Africa. Vol. 2, $2^{\text {nd }}$ edition. Royal Botanic Gardens, Kew, pp. 62-63.

12 Igbe, I., Omogbai, E.K.I. and Ozolua, R.I. (2009). Hypoglycaemic activity of aqueous seed extract of Hunteria umbellata in normal and streptozotocin-induced diabetic rats. Pharmaceutical Biology 47(10): 1011- 1016.

13 Okonta, J.M. and Aguwa, C.N. (2007). Evaluation of hypoglycaemic activities of glycosides and alkaloids extracts of Picralima nitida Stapf. (Apocynaceae) seed. International Journal of Pharmacology 3(6): 505-509.

14 Prince, P.S.M. and Menon, V.P. (2001). Antioxidant action of Tinospora cordifolia root extract in alloxan diabetic rats. Phytotherapy Research 15(3): 213-218.

15 Srivastava, Y., Venkatakrishna-Bhatt, H. and Verma, Y. (1988). Effect of Momordica charantia Linn. pomous aqueous extract on cataractogenesis in murine alloxan diabetics. Pharmacology Research Communications 20: 201-209. 
17 Svoboda, G.H., Gorman, M. and Root, M.A. (1964). Alkaloids of Vinca rosea (Catharanthus roseus): A preliminary report on hypoglycaemic activity. Llyodia 27: 361-363.

$18 \quad$ United States National Institutes for Health publication (1985),. no. 85-23.

19 Vats, V., Yadav, S.P., Biswas, N.R. and Grover, J.K. (2004). Anti-cataract activity of Pterocarpus marsupium bark and Trigonella foenum-graecum seeds extract in alloxan diabetic rats. Journal of Ethnopharmacology 93: 289-294.

20 Yang, J.H., Li, Z.Y., Li, L., Wang, Y.X., (1999). Diterpenoids Alkaloids from Aconitum episcopale. Phytochemistry 50: 345-346.

22 Yoshikawa, M., Morikawa, T., Matsuda, H., Tanabe, G. and Muraoka, O. (2002). Absolute stereostructure of potent $\alpha$-glucosidase inhibitor, Salacinol, with unique thiosugar sulfonium sulphate inner salt structure from Salacia reticulata. Bio-organic and Medicinal Chemistry 10(5): 1547-1554.

23 Yoshikawa, M., Nakamura, S., Ozaki, K., Kumahara, A., Morikawa, T. and Matsuda, H. (2007). Structures of steroidal alkaloidals oligoglycosides, robeneosides $A$ and $B$, and antidiabetogenic constituents from the Brazilian medicinal plant, Solanum lycocarpum. Journal of Natural Products 70: 210-214. 